\title{
Survey on Perceived Impact of Religion, Culture, and Social Network Information on Surrogate Decision-making in a South Asian Developed Country
}

\author{
Shahla Siddiqui, Sukhanya Sureish, Audris Chia \\ Department of Anaesthesiology and Intensive Care, Khoo Teck Puat hospital, Singapore
}

Abstract

Introduction: Relatives often have to assume responsibility for making end of life choices as surrogate decision-makers for patients with diminished or are lacking capacity. Our aim was to study the influence of religion, culture and social network information on surrogate decision making. Methods: This study was an exploratory, prospective, survey. Questions addressed the role of surrogates in decision making and the importance and influence of religion, culture and social media on such decisions. Results: 34 respondents filled out the anonymous survey. Surrogate decision making is a complex process and influenced by many factors. Conclusion: This survey points to a need for wider studies looking at the factors influencing people when making such important decisions and further social psychology interventions to evaluate whether such decisions can be made more consistent and patient centred.

Keywords: Culture, religion, social media information, surrogate decision making

\section{INTRODUCTION}

Relatives often have to assume responsibility for making end-of-life choices as surrogate decision-makers for patients with diminished or are lacking capacity. A recent study found that the scope and frequency of surrogate decision-making (SDM) are much more extensive than previously thought, and concluded that hospital care should be organized to support their large and growing role in making health-care decisions. ${ }^{[1]}$

Key ethical principles for SDM are substituted judgment (what decision would the patient have made if she were able to make decisions) and the best interest standard (what would be the best outcome for the patient based on a holistic assessment of her possible and relevant interests). ${ }^{[2]}$ There are, however, significant and persistent issues with SDM, including the frequent failure of surrogates to make decisions that accord with what patients would have wanted. ${ }^{[3]}$ A shared decision model has been espoused for the best interest decision-making, in which physicians and surrogates reach a decision together regarding the health-care options or goals of care. ${ }^{[4]}$ While many times physicians and surrogates agree on the best outcome for patients (68\%), they may diverge due to the

\begin{tabular}{|l|l|}
\hline \multicolumn{3}{|c|}{ Access this article online } \\
\hline Quick Response Code: & Website: \\
\hline & www.ijccm.org \\
\hline & \\
\hline
\end{tabular}

surrogates' misunderstandings about physicians' prognosis assessment and discordant beliefs on patients' prognoses. ${ }^{[5]}$ Conflicts may also arise if judgments on what the patient would have wanted and judgments on her best interests diverge. Other factors include financial costs and burdens as well as cultural and religious beliefs and values. ${ }^{[6]}$

Many aspects of SDM have been studied, and much have been suggested and debated on how to improve the process. ${ }^{[7]}$ Proposed methods to improve SDM include the use of social networks, in ascertaining patient's preferences ${ }^{[8]}$ There are, however, very few surveys or studies on the influence and significance of social network information on SDM.

\section{Aims}

The aim was to study the influence of religion, culture, and social network information on SDM.

Address for correspondence: Dr. Shahla Siddiqui, Department of Anaesthesiology and Intensive Care, Khoo Teck Puat hospital, Singapore. E-mail: shahlasi@yahoo.com

This is an open access journal, and articles are distributed under the terms of the Creative Commons Attribution-NonCommercial-ShareAlike 4.0 License, which allows others to remix, tweak, and build upon the work non-commercially, as long as appropriate credit is given and the new creations are licensed under the identical terms.

For reprints contact: reprints@medknow.com

How to cite this article: Siddiqui S, Sureish S, Chia A. Survey on perceived impact of religion, culture, and social network information on surrogate decision-making in a South Asian developed country. Indian J Crit Care Med 2018;22:656-9. 


\section{Methodology}

This study was an exploratory, prospective survey. After ethics approval was obtained, an anonymized survey was made available to nonhealth-care-related professionals in the anesthesia and surgical departments of a tertiary care hospital.

Strict anonymity was maintained. Descriptive and inferential statistics were used in looking for relationships. The questions used were derived from the literature to form a novel tool. This was further validated and revised after testing on five participants. These questions addressed the role of surrogates in decision-making and the importance and influence of religion, culture, and social media on such decisions. These questions asked the following: Will you make a health-care decision for your loved ones? Have you made such a decision? Would it matter if the health-related decision is not in line with your belief? The decision is in line with the patient's religion but different from yours, would you agree? Does social media influence your decision about your loved one's health? Decided to follow what the family decides, but came across a social media comment made by the patient that they do not agree with nonbeneficial life support in the intensive care unit. Would such a comment affect your decision? Case vignettes were also used to elicit a response on the influence of religious views on decision-making. This included the following: Supposing your loved one has different religious views than you, would you based your decisions on what you believe in or what you feel your loved one would have wanted? To ask about factors influencing decision-making the following question was asked: What is more important in your opinion when doctors decide about health-care choices for your incapacitated loved one? The choices included: best interest of the patient as decided by the doctor, family decision, and perceived wish of the patient as shown in a legal document. As this was an anonymous survey, families were not counseled in any way.

\section{RESULTS}

A total of 34 respondents filled out the anonymous survey. Figures 1-3 show the demographic distribution. About 79\% were females and $82 \%$ were Chinese (while $12 \%$ were Malays and $6 \%$ were Indians). About $59 \%$ were married, and the average age was 35 years. The majority (82\%) of people felt that they would make health-care decisions on behalf of their loved ones, but of these people, $57 \%$ have not done it before. In a hypothetical scenario (see attached questionnaire) where a decision for end-of-life care needs to be made for limiting life-sustaining therapy (Q8), 70\% preferred to ask close family for the decision. $66 \%$ felt that it would not matter if the decision was not in line with their beliefs. About $88 \%$ felt that if the decision was in line with their religion which is different from theirs, they would agree to it. The respondents were divided $50 \%-50 \%$ when it came to the influence of social media preferences of the patient. When asked (Q11) that if the family decision was in opposition to a social media post made by the patient previously, $65 \%$ stated that they would

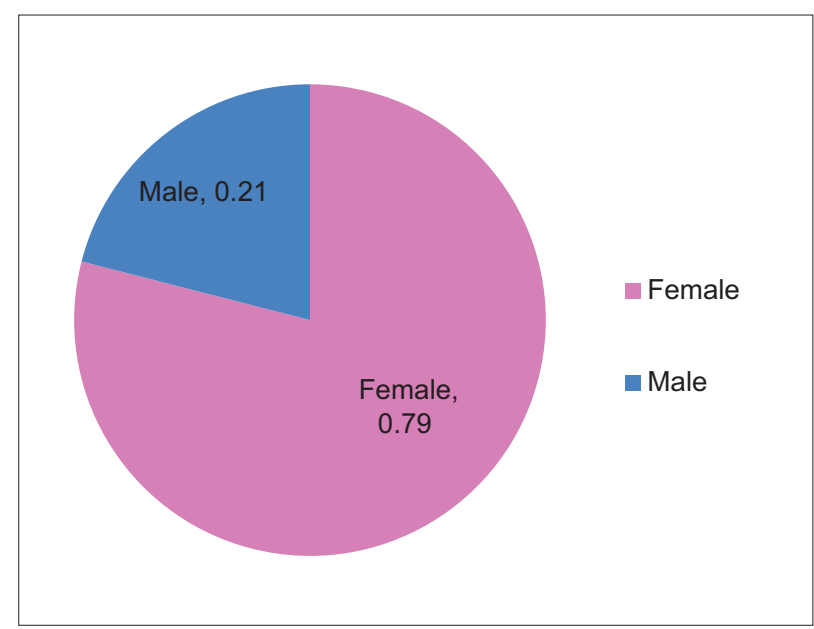

Figure 1: Demographics of participants according to gender

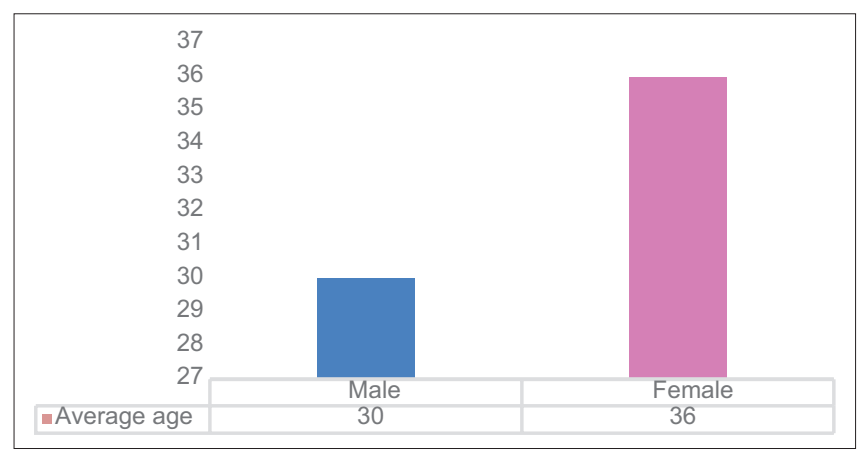

Figure 2: Average age of participants

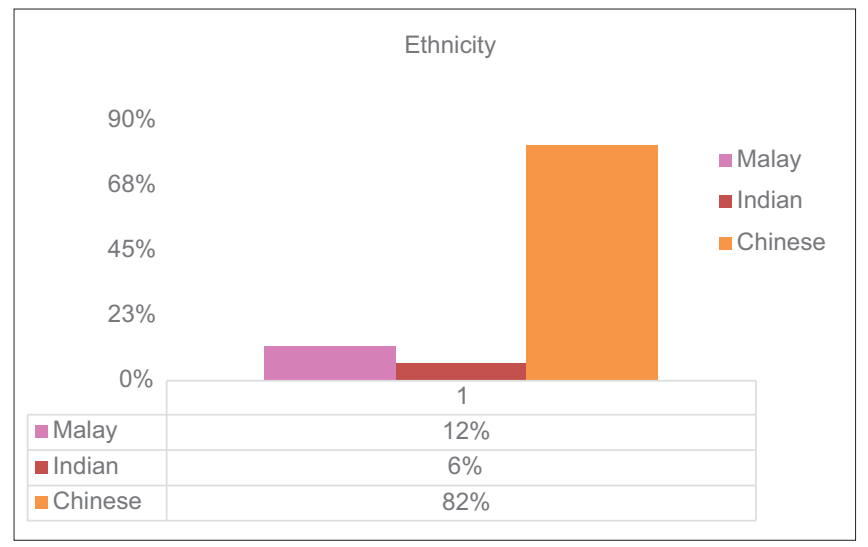

Figure 3: Demographics of participants according to ethnicity

not change their decision subsequently. However, $65 \%$ felt that they would make a decision close to what the patient would have wanted over a decision with a clear benefit to the patient, their religion, values, or family tradition. $97 \%$ also stated that they would choose a decision based on their loved one's views (the patient) rather than their views. When asked what is more important when physicians decide about health-care choices for an incapacitated loved one, $44 \%$ felt it was the best interest decision as decided by the doctor, while $44 \%$ felt it was the perceived wish of the patient as shown in a 
legal document. Finally when asked whether these days social networks provide accurate information about a person's beliefs and preferences, $88 \%$ said no.

Table 1 displays the participant's answers for questions on the importance of beliefs, religion, and social media; Table 2 shows the answers to a hypothetical scenario on the influence of religious views on decision-making; and Table 3 illustrates factors that are important in the decision-making process.

\section{Analysis}

The demographic distribution was uneven with the majority being Chinese women; however, this could represent the profile of people working as nonhealth-care administrative staff in a typical hospital office. Most people felt that although they have not made health-care decisions for their loved ones, they will do so in the future. There were several contradictions in the answers which could mean a lack of understanding the questions clearly or a lack of certainty and indecision

\begin{tabular}{lcc}
\hline $\begin{array}{l}\text { Table 1: Participant's answers to questions on the } \\
\text { importance of beliefs, religion, and social media }\end{array}$ & \\
\hline & Yes (\%) & No (\%) \\
\hline $\begin{array}{l}\text { Will you make health-care decisions for your } \\
\text { loved ones }\end{array}$ & $28(82)$ & $6(18)$ \\
Have you made such a decision? & 57 & 43 \\
Would it matter if the health-related decision is & $11(34)$ & $21(66)$ \\
not in line with your belief? & & \\
$\begin{array}{l}\text { The decision is in line with the patient's religion } \\
\text { but different from yours, would you agree? }\end{array}$ & $30(88)$ & $4(11.8)$ \\
$\begin{array}{l}\text { Does social media influence your decision } \\
\text { about your loved one's health? }\end{array}$ & $17(50)$ & $17(50)$ \\
$\begin{array}{l}\text { Decided to follow what the family decide, but } \\
\text { came across a social media comment made } \\
\text { by the patient that they do not agree with } \\
\text { nonbeneficial life support in ICU. Would such } \\
\text { comment affect your decision? }\end{array}$ & $11(32)$ & $22(65)$ \\
\hline $\begin{array}{l}\text { ICU: Intensive care unit } \\
\end{array}$ & & \\
\hline
\end{tabular}

\begin{tabular}{|c|c|}
\hline \multicolumn{2}{|c|}{$\begin{array}{l}\text { Supposing your loved one has different religion views than you, } \\
\text { would you based your decisions on what you believe in or what } \\
\text { you feel your loved one would have wanted? }\end{array}$} \\
\hline Your views & $1(3)$ \\
\hline Your love ones views & $33(97)$ \\
\hline
\end{tabular}

Table 3: Factors that are important in the decision-making process

What is more important in your opinion when doctors decide about health-care choices for your incapacitated loved one?

Best interest of the patient as decided by the doctor 15 (44)

Family decision 3 (9)

Perceived wish of the patient as shown in legal document 15 (44)

Family decision and perceived wish of the patient as 1 (3)

shown in a legal document when potentially faced with such scenarios. For example, of the 11 people who said yes in Q8 (yes it would matter if the decision is not in line with their beliefs), only three of them said that they would not agree if the decision taken was in line with the patient's decision but not theirs. Of the people who stated that social media preferences would influence their decisions, only half were consistent in the hypothetical scenario (Q11) (from $50 \%$ yes to $66 \%$ no for the influence of social media). Based on the responses, family decisions superseded patient preferences, and the same pattern was seen with social media preferences by the patient. This pattern was more evident in a case scenario while when asked about choosing what the patient would have wanted, 95\% stated that this was their choice. It seems that people differed in their attitudes (outlook) versus their actual behaviors (hypothetical scenarios). The doctor's opinion as to what is best for the patient was held in high regard and at the same level as what is the perceived wish of the patient. On the topic of social media, the majority (88\%) said that social network does not provide accurate information of what they or their loved ones believe in; however, of the 30 people who said that social media was inaccurate, 13 people said that it will still influence their decisions.

\section{Discussion}

SDM is a complex process and influenced by many factors. Very few studies have actually asked potential surrogates regarding what they perceive would influence them when making health-care decisions for their incapacitated loved ones in critically ill situations. This short and limited survey samples a cross section of such people, and it emerges that family-based decisions take precedence over patient's stated preferences. It underlines the importance of the family's role in decision-making and thereby brings up the influence of culture. While individual patient autonomy is highly valued in Western culture, Asian culture considers illness and death as affecting the entire family and not just the patient, and so a wider relative autonomy prevails. ${ }^{[9]}$ There were significant conflicting opinions and contradictions among people when asked regarding specific factors influencing their decisions, and most people did not trust social media preferences of their loved ones. This survey points to a need for wider studies looking at the factors influencing people when making such important decisions and further social psychology interventions to evaluate whether such decisions can be made more consistent and patient centered.

\section{Financial support and sponsorship \\ Nil.}

\section{Conflicts of interest}

There are no conflicts of interest.

\section{References}

1. Elwyn G, Frosch D, Thomson R, Joseph-Williams N, Lloyd A, Kinnersley $\mathrm{P}$, et al. Shared decision making: A model for clinical practice. J Gen Intern Med 2012;27:1361-7. 
2. White DB. Rethinking interventions to improve surrogate decision making in Intensive Care Units. Am J Crit Care 2011;20:252-7.

3. Torke AM, Sachs GA, Helft PR, Montz K, Hui SL, Slaven JE, et al. Scope and outcomes of surrogate decision making among hospitalized older adults. JAMA Intern Med 2014;174:370-7.

4. AMA Code of Medical Ethics. Available from: http://www.ama-assn. org/ama/pub/physician-resources/medical-ethics/code-medical-ethics. page. [Last accessed on 2016 Aug 28].

5. Shah RD, Rasinski KA, Alexander GC. The influence of surrogate decision makers on clinical decision making for critically ill adults. J Intensive Care Med 2015;30:278-85.

6. Surrogate decision making: Families are much more than visitors. Available from: http://www.kevinmd.com/blog/2014/03/ surrogate-decision-making-families-visitors.html. [Last accessed on 2016 Aug 28].

7. Moore JA, Gallagher CM. Are we prepared for surrogate decision making in the internet age? Am J Bioeth 2012;12:47-9.

8. Fritsch J, Petronio S, Helft PR, Torke AM. Making decisions for hospitalized older adults: Ethical factors considered by family surrogates. J Clin Ethics 2013;24:125-34.

9. Ho ZJ, Radha Krishna LK, Yee CP. Chinese familial tradition and western influence: A case study in Singapore on decision making at the end of life. J Pain Symptom Manage 2010;40:932-7. 